\title{
Network Approaches to Interbank Markets: Foreword
}

\author{
Simone Alfarano • Daniel Fricke • Thomas Lux • \\ Matthias Raddant
}

The 2007-2009 global financial crisis has brought to the fore the importance of the network of claims and liabilities emanating from the close ties between financial institutions. The potential of contagious domino effects within such networks and various shock transmission channels within the banking system have become a major concern for macro-prudential regulation. The analysis of these connections requires new instruments of analysis that have not been used in economics before.

The papers in this special issue of Computational Economics are the outcome of a workshop held under the auspices of the University Jaume I, Castellón, Spain (UJI) at the Hotel Palasiet in nearby Benicassim in May 2013. The workshop brought together researchers from various countries and fields. It covered empirical studies

\section{S. Alfarano}

Department of Economics, Universitat Jaume I, 12071 Castellón, Spain

D. Fricke

Saïd Business School, University of Oxford, Park End Street, Oxford, UK

D. Fricke

Institute for New Economic Thinking at the Oxford Martin School, Oxford OX2 6ED, UK

T. Lux

Department of Economics, University of Kiel, 24118 Kiel, Germany

T. Lux

Banco de España Chair for Computational Economics, Universitat Jaume I, 12071 Castellón, Spain

M. Raddant

Kiel Institute for the World Economy, Kiellinie 66, 24105 Kiel, Germany

M. Raddant $(\varangle)$

Department of Economics, University of Kiel, Kiel, Germany

e-mail: raddant@economics.uni-kiel.de 
on networked systems, the behavior of banks, as well as studies on contagion and systemic risk. Four of these contributions are presented on the following pages.

The article by Sam Langfield and Kimmo Soramäki gives a survey on Interbank Exposure Networks. They highlight the multitude of different types of connections between financial institutions and describe the statistical features of these networks. They also discuss different approaches to identify key players in financial networks.

The second paper provides a Centrality Measurement of the Mexican Large Value Payments System from the Perspective of Multiplex Networks. This paper by Bernardo Bravo-Benitez, Biliana Alexandrova-Kabadjova and Serafin Martinez-Jaramillo uses a very rich data set of payments which are analyzed as a multiplex network. The authors show that the networks of payments between participants and third parties are dissimilar and that the identification of critical nodes is subject to a prior identification of relevant payment types.

In Cascades in Real Interbank Markets Fariba Karimi and Matthias Raddant use empirical data to calibrate a simulation study on counterfactual cascades in interbank markets. The outcomes of these simulations are compared to cascade simulations based on different network models (null models). It is shown that an accurate modeling of the size distribution of banks is critical to generate outcomes close to those based on the empirical data. It is further shown that the relative accuracy of different null models changes for different levels of capitalization of the banking system.

The fourth paper focuses on Bank capital shock propagation via syndicated interconnectedness. Makoto Nirei, Julián Caballero and Vladyslav Sushko bring forward a very detailed model of loan syndication, calibrated with empirical data. They show how capital constraints can propagate idiosyncratic shocks of single institutions to other market participants under different network structures. The empirically found core-periphery structures appear to be more robust compared to alternative network topologies.

Finally we would like to express our gratefulness to the contributors of this special issue and to all participants of the workshop in Benicassim, for their stimulating contributions and lively discussion at this meeting by which also quite a number of new projects and collaborations have been motivated. We are also most grateful for the financial support that was granted by the Banco de España Chair at UJI and the Kiel Institute for the World Economy.

Acknowledgments We thank Eva Camacho and Andrea Teglio for their participation in the organization of the NAIM workshop that took place in Benicassim from 30th until 31st May, 2013. 